\title{
The tactics behind public transport procurements: an integrated actor approach
}

\author{
Lisa Hansson
}

Received: 5 February 2011 / Accepted: 7 September 2011 /Published online: 6 October 2011

(C) The Author(s) 2011. This article is published with open access at SpringerLink.com

\begin{abstract}
Purpose In striving for a "successful" public transport system, functional procurement operations are needed. The "Scandinavian model" has gained popularity in Europe, prompting considerable research into relationships between government and private transport operators. To understand the Scandinavian model, one must also identify the roles governmental actors and institutions play when interacting in procurement processes. This article aims to provide an understanding of the interrelationships between the actors involved in planning a public transport procurement process.

Method The method used is case study method and in specific process tracing. The empirical data consist of public documents and interviews concerning the work with a public transport procurement, located to a Swedish county.

Results The article demonstrates power relationships between the actors and identifies how resources are deployed to maximize influence while minimizing dependence on other actors. It also shows that there is a dominant coalition that employs strategies within the rules of the game to regulate the process of exchange.

Conclusion The article conclude that the procurement entity is the dominant organisation and that the actors working within it form a dominant coalition. The procurement entity, however, is dependent on political and financial resources from the principals to achieve its agenda.
\end{abstract}

Keywords Public transport Public procurement .

Power resources $\cdot$ Scandinavian model

L. Hansson $(\bowtie)$

Swedish National Road and Transport Research Institute,

581 95, Linköping, Sweden

e-mail: lisa.hansson@vti.se

\section{Introduction}

Many components of a transport system are procured, for example, busses and ICT services. In striving for "successful" public transport systems, good public procurement models are therefore needed. The "Scandinavian model" has gained popularity in Europe, prompting considerable research into the formal structures linking government and private operators [1]. In the Scandinavian model, public authorities are responsible for drawing up specifications for public transport service, which is then purchased from private or public companies via a tendering process [2, p. 30, 3]. This article focuses on an under investigated part of the Scandinavian model: the interrelationship between the governmental actors involved in procuring public transport. Using the terms principal-agent, the Scandinavian model on governmental level is organized as a multiple principal (municipalities, county councils and regional cooperation body) relation with one agent (the PTA).

Understanding power in the Scandinavian model entails identifying the roles actors and institutions play when they interact in procurement processes [1]. Research demonstrates that goal conflicts still arise between actors in the model [4-6]. For example in Sweden local and regional politicians have criticized the procurement entity, often located in the public transport authority (PTA), for having considerable autonomy and have taken a dominant position in planning the tender [7-9]. This may be seen as problematic from a democratic point of view, as it may reduce the possibility of political involvement in the process as well as reduce the possibility to hold politicians accountable for public decisions. [10]. Research in other policy areas have shown that a great amount of power lies within a procurement unit, but no study has thou actual 
analysed and critically examined the power relationships that exist in the Scandinavian model of public transport; how is power gained, maintained and controlled? It is also very difficult to identify international studies focusing on the power relationships between actors in public transport procurement situations $[10,11] .^{1}$

This article aims to provide an understanding of the interrelationships between the actors involved in planning public transport procurements, with a focus on the power relations between involved actors. More specific I will analyse power relationships between the actors in a Swedish procurement process and analyse how resources are deployed to maximize influence while minimizing dependence on other actors.

The article's main contribution is that it takes an integrated approach to understanding the relationships between actors and institutions, across government, involved in procuring public transport. Empirical as well theoretical research into this matter is lacking, and more attention is required on the part of both researchers and practitioners (see, e.g., $[11,13])$.

\section{Theoretical point of departure}

The theoretical framework concerns the understanding of power in a decision-making process in which several actors interact. Early scholars in political science often focused on who had power by viewing the formal structures of power, i.e. seeing the politicians as decisions makers and therefore prescribing them to be most powerful [14]. This view has then been criticized and it has been shown that it is other actors that actual manifest and uses its power, sometimes undermining the formal structures [15]. By focusing on actors' interaction with each other in actual decision making process several different power relations, and strategies used to maintain or change agendas may be identified. This article takes point of departure in understanding and analyzing power as something relational, i.e. power is manifested in the interaction between two or several actors [16]. Rhodes' theory of power dependence will be used in order to analyse and explain the empirical data [17]. This theory sees both principals and agents as parts of a network; it addresses the fact that different actors (i.e., agents or principals) may have different power resources (e.g., constitutional, legal, organizational, finan-

\footnotetext{
${ }^{1}$ Some studies describe the formal organization of public transport solutions in various countries (see, e.g., [3, 12]), but these studies do not emphasize analysing the actual actor roles or the effects of various actors on the outcome of a process. Instead, the description of the organizational solutions is addressed when analysing a (different) main purpose, for example, reduced costs in tender agreements (see, e.g., [2]).
}

cial, political, and informational resources), and stresses that actors have more or less control over their various resources [18]. For example, the procurement entity may have informational advantages and professional resources, but might not have the necessary financial or political resources in the decision-making process.

Rhodes' power-dependence framework has been outlined several times (see, in particular, [17] and [19]); this section summarizes its key features. The power-dependence framework, used to explore linkages between organizations within a network, rests on five propositions:

1. An organization is dependent on other organizations' resources.

2. To achieve their goals, organizations (or the actors within them) must exchange resources.

3. Decision-making in organizations is constrained by the existence of other organizations within the network, but a dominant coalition retains some discretion.

4. The dominant coalition (consists of the network of individuals located in one or several organizations) employs strategies within the rules of the game to regulate the exchange process.

5. Variations in the degree of discretion result from the goals and relative power potential of each interacting organization. This relative power potential is a product of the resources of each organization, the rules of the game, and the exchange processes between organizations $[19$, p. 42].

Rhodes demonstrated that no single actor possesses all the constitutional, legal, organizational, financial, political, and informational resources it requires to achieve its goals. Therefore, a exchange of resources is the necessary outcome. This means that the individual levels of government may be hierarchically organized, but their relationships with other levels are characterized by interdependence $[20]^{2}$ For example, for a municipality to strengthen its political resources, it may seek cooperation with other municipalities that it believes exert strong influence over the political decision-making process [22].

Rhodes' model portrays the actors as participants in a complex game in which they manoeuvre for advantages; each actor seeks to deploy the resources it has at its disposal while maximizing its influence and minimizing its dependence on the other players. [20]. I will use Rhodes' theory when trying to understand and analyse the actors involved in planning a public transport procurement process, by asking, for example: How do they exchange resources? What game is being played? Who forms the dominant coalition? The benefit of using this theory is that it helps us

\footnotetext{
${ }^{2}$ This is often highlighted in the governance perspective on decision making; for further discussion of governance, see Pierre [21].
} 
grasp any differences that may exist between principals, encompassing both vertical and horizontal interaction between them [23].

\section{Method}

The empirical data is based on a case study of a single procurement process in a Swedish county. The choice of case was strategic and based on several criteria. The first criterion was made according to achieve representation, i.e. it was important to chose an procurement that was made in a context that could be seen as representative for the institutional features of the Scandinavian model in Sweden. The procurement should therefore have to have occurred in a county where the public transport authority is $50 \%$ county council owned and 50\% municipally owned. The county should also have a regional cooperation body. This was important though joint ownership and an additional regional cooperation body is the most common organisational structure in this context in Sweden. Based on this first criteria, other criterion were then used to narrow down the selection, for example, due to the tendency criterion, it was important to choose an procurement that was recently conducted [24].

Case study method, and in specific process tracing has been the main method used for selecting and analysing the empirical data within the county. In process tracing, the researcher following a processes and examines the data in relation to the process. The data comes ideally from a wide range of sources [25]. The benefit of using several types of data is that the collected data can be cross-checked across multiple sources, which increases the robustness of the findings [26].

I have reviewed the events based on public documents and interviews, where the main data source is public documentation, comprising mainly protocols, letters, and reports, totalling approximately 1350 documents. This material dates from 2003-2009 and was collected from the 12 municipalities in the studied county, the public transport authority, the county council, and the regional cooperation body. Documents are commonly used when trying to identify power relations within a process. The benefits of using documents are several; it gives information on different events (who participated? Who was invited? What decisions were taken?); it provides information of accessible and used resources (for example financial reports or delegation schemes) [25]. In this study the documents were analysed in chronological order and was used to reconstruct the process and gain an understanding of the various actions and events occurring during the processes. The documents were also used to identify key actors, and serve a control function in relation to the interviews. As with all data sources, there are some weaknesses. One is that it may be difficult for a researcher to access the documents. In this study it has been limited access problems, mainly due to "the principle of public access to official documents" that is incorporated into Swedish law. This means that all documents (included received or dispatched letters, decisions and reports) from government organizations are in principle public documents, and must be made available for anyone to read [27]. Another weakness of using documents as a source is that it may include incomplete information regarding the events taken. By including multiple types of documents (protocols, letters, e-mails etc.) I tried to get a broader picture of the process. It is also important to use other type of data sources [25]. In addition to reviewing the public documents, I conducted 18 semi-structured interviews. Key people involved in procuring or planning the procurement of public transport, i.e., politicians and public servants from seven of twelve municipalities, the county council, and regional cooperation body as well as the public transport authority, were interviewed. I selected the municipalities based on factors that distinguished them from each other, for example, population, size, and geographic location, but also based on their activity/lack of activity in the procurement process as revealed in the public documents. I chose interviewees based on the delegation chain in relation to responsibility for public transport in each organization. For example, to capture the political level in each municipality, I chose to interview the municipal board chairmen, as all political public transport decisions are made by the board. I also interviewed the civil servants working on public transport or public transport procurement issues. Notably, in many smaller municipalities, only one civil servant works on public transport and its procurement; larger, average-sized municipalities may employ two or more. I used the information found in the document study combined with my overall aim when constructing the interview guide. The questions were relatively open; I generally asked the respondents to describe the procurement processes and, while they were doing so, asked additional questions. The interviews lasted one to two hours and were in most cases conducted at the respondent's office or in a conference room. In addition to the 18 interviewees, I also attempted to make interview appointments with four others, but for various reasons (e.g., lack of time, lived abroad, and lack of response to the request) failed to make appointments with them. Early studies of power used interviews more as objective facts, asking the respondents "who do you think have power?" and then defined the power to the actor that got most responses [14]. In process tracing interviews rather has the purpose provide information that complements the findings in document study. It may provide information that is not found in the documents, for example 
attitudes towards other actors or informal actions that has taken place in the process. Interviews are seen as sources that are subjectively constructed by the respondent [25]. This due to the problem of reliability that comes with interviews; the respondent may be inaccurate in his/hers response due to poor recall or he/she may have a hidden agenda. Also the construction of questions may be poorly made. In order to prevent such biases it is important to cross check the interview response with the document data. In order to prevent poorly asked questions it important to have a clear understanding of the case; the key actors involved and the key events that has taken place [27]. By conducting the document study before the interview study, I limited the possibly of poor research questions and made it possible to cross check the respondents answers.

I then used the theoretical foundation of Rhodes in a "theory-consuming" way, meaning that I use the theory to sort out, analyse, and explain the outcomes found in the empirical material [27]. This means that the theory is not tested in a hypothetical way; instead it is used to help me understand and interpret the actions taken in the case [28]. In the article I use interviews and documents in order to illustrate events or examples found in the empirical material. The event illustration doesn't have to be representative for all actors in the process, instead they are pointed out as illustration because they had an impact on the process, and for example it may be an example of a strategy that was used by one actor in order to influence another actor [28].

\section{Empirical findings}

The empirical findings are based on analysing a planning process when procuring public transport. The studied procurement concerns planning regional public bus routes, regional transport services (mainly busses, in total 250), and some local transport services (school busses) [29]. It is a large procurement with contracts lasting 7 years.

The main organizations involved in this process are the county council, 12 municipalities, the regional cooperation body, and the public transport authority (PTA) (See Fig. 1). The PTA is the procurement entity in this case. Seen from the principal-agent relationship perspective, the county council, municipalities, and regional cooperation body are principals relative to the procurement entity, which is here seen as an agent.

The formal constitutional-legal framework sets the rules of the game. The relationship between the organizations is formalized in a legal document stating that the county council and the 12 municipalities in the county own the procurement entity. This means that the county council and municipalities are financially responsible for the procure-

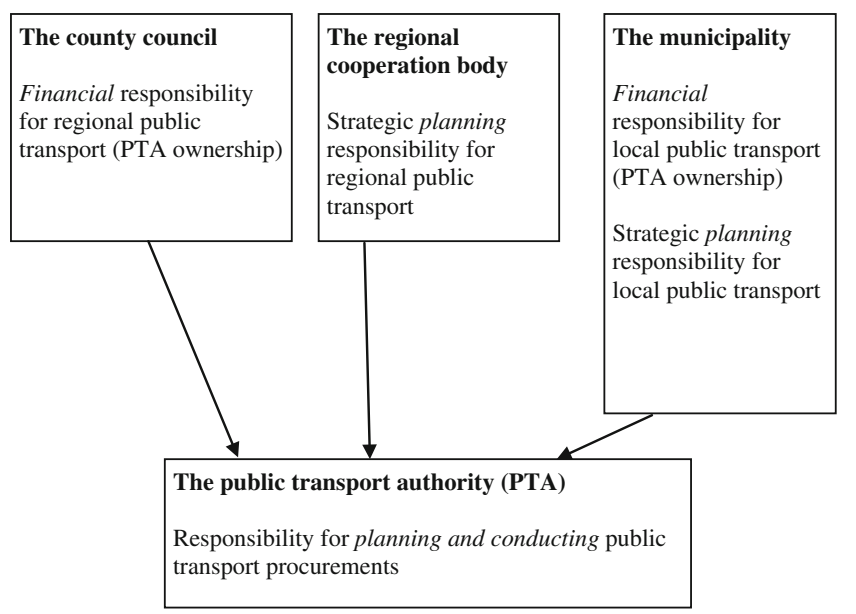

Fig. 1 The formal division of responsibility for public transport between principals and the agent on the local governmental level in Sweden

ment entity and for financing regional and local public transport not covered by ticket sales [30].

The county council and the municipalities have divided the financial responsibilities, the county council financing regional public traffic in the county and the municipalities financing local public traffic. This means that a regional bus line that traverses a municipality is financed by the county council, but a bus line that only operates within municipal boundaries is financed by the municipality. The municipalities are also responsible for strategically planning local public transport.

The county council and the municipalities each have a directly elected political board and civil servants working in the public administration. Within their organizations, the county council and the municipalities choose political representatives to serve on the PTA. Today, five politicians serve on the PTA, making up the PTA board. The PTA is led by a president, not politically elected. In addition, civil servants work in the PTA administration.

The PTA is legally organized as a public company; it is responsible for fulfilling the demands of the PTA board (i.e., the owners' wishes), but has considerable latitude to make decisions on its own, as long as these decisions do not oppose the wishes of the PTA board.

The regional cooperation body has a non-financial relationship with the PTA and is responsible for strategic regional traffic planning in the county. The regional cooperation body consists of political representatives from the county council and the 12 municipalities and serves as a "meeting place" for discussing county issues. The regional cooperation body also includes civil servants working in the public administration.

In Rhodes' terms [19], the formalized relationship, set by the legal-constitutional framework, can be seen as the rules of the game of the procurement process. This type of 
framework is the most commonly used when it comes to organising public transport in Sweden. In short, the principals have made the PTA responsible for planning and conducting the procurement. However, this responsibility is not delegated without constraints. The PTA is dependent on both financial and political approval from the principals, before it can finalize the procurement. Thus the PTA must consider the planning strategies and political requests of the principals and adopt the services to be procured within a budget set by the principals.

As Rhodes [19] argues, however, actors may change the rules of the game and different resources may be used. In this empirical section, I will use findings pertaining to a planning process to analyse and describe the actual game played between the various actors and their use of power resources.

The planning process will not be described in depth; I will instead focus on certain points in the process that illustrate the actors' interrelationships and the power resource dependency/mobilization that may emerge from the interrelationships. The planning process will be described chronologically, but emphasizing an analytical structure that highlights the interrelationships and power resources. The overall process is present in Fig. 2, which may be useful to refer to when reading the empirical findings.

\subsection{PTA strategies for mobilizing political resources}

As stated above, the formal agreement between the municipalities, county council, and PTA specifies that the PTA should have the main responsibility for conducting the procurement. However, to conduct the procurement, the PTA also needs financial and political resources from the principals: political resources in the form of approval from each principal's political board (e.g., all involved municipal boards) and financial resources in the form of a procurement budget. This first section will present examples of how the PTA strove to gain political resources.

\subsubsection{Take initiative to create dialogue}

One clear PTA strategy was to create dialogue with the principals throughout the procurement process, while maintaining power over the process. To achieve this, the
PTA president appointed a civil servant to work full time on planning the procurement [31]. This civil servant had been working at the PTA for a long time and was known to be precise and well informed on all public transport issues. In this way, the PTA tried to maintain its information advantages, and to display its public transport expertise to the principals. However, appointing this employee was a risk for the PTA, since he was not popular among some principals; for example, some municipal civil servants described him as a "traditional man" and said he was used to doing things "his way" [32].

To gain the principals' respect, the PTA president first wrote to the contact people (i.e., civil servants) working for the principals, stating his mission and inviting them to enter into dialogue. Then a few weeks later, the PTA employee sent a letter to the principals. The PTA president thought it was important to send out a letter of his own first. He wanted to signal to the principals that he, as president, supported the decision to appoint this specific employee to retain the main responsibility for the procurement process [31]. Both letters communicated approximately the same information: how the procurement process was to proceed and the PTA's expectations of the principals [33]. The PTA asked the principals to provide a list of the demands (for example safety-, environmental aspects etc.) they wished to be included in the procurement; it also wanted political involvement, not just civil servant involvement:

There is an explicit request, from the PTA board, that the owners attending these meetings should be represented by at least the executive committee of the municipality or similar for the regional cooperation body/county council. [34]

The letters can be seen as both a strategy for initiating dialogue and as a PTA attempt to specify the rules of the game still further (e.g., establish who is in charge and what the PTA expects the principals to do).

The PTA employee visited all the municipalities and the county council. A civil servant from one municipality described the meeting as a disappointment, because he felt true dialogue was lacking. The civil servant had prepared for the meeting by inviting the head politicians and civil servants in the municipality, according to PTA wishes. The civil servant had also summarized their requirements for the procurement. However, the time for dialogue between the
Fig. 2 The chronological order of the planning process described in this article

\begin{tabular}{|c|c|c|c|c|c|}
\hline \multicolumn{6}{|l|}{ Start } \\
\hline $\begin{array}{l}\text { Planning } \\
\text { process is } \\
\text { initiated }\end{array}$ & $\begin{array}{l}\text { Meetings with } \\
\text { principals; the } \\
\text { PTA is gathering } \\
\text { information }\end{array}$ & $\begin{array}{l}\text { The PTA } \\
\text { summarizes the } \\
\text { information into a } \\
\text { pamphlet }\end{array}$ & $\begin{array}{l}\text { The pamphlet is } \\
\text { circulated to the } \\
\text { principals for } \\
\text { their comments }\end{array}$ & $\begin{array}{l}\text { The regional } \\
\text { cooperation body } \\
\text { relives new } \\
\text { information that } \\
\text { may affect the } \\
\text { process }\end{array}$ & $\begin{array}{l}\text { The PTA writes } \\
\text { the final } \\
\text { procurement } \\
\text { document. End of } \\
\text { the planning } \\
\text { process }\end{array}$ \\
\hline
\end{tabular}


PTA and the municipality never arrived, according to the civil servant in the municipality. He said that the PTA employee presented a draft document about the need for the procurement and informed them about the process. The civil servant also had the impression that municipal requirements were not evident in the material the PTA employee presented [32]. The civil servant in the municipality stated:

I was surprised. There was nothing specific to the municipality, but more regional issues, topics we feel we cannot affect that much anyway, because other actors - the regional cooperation body and PTA itself - have overall responsibility for all the municipalities together. [32]

The suggested requirements that the civil servant had prepared were not discussed; instead the PTA employee asked the civil servant to submit the list after the meeting [32].

Clearly, the PTA had formally expressed a desire for the political level to become involved in the procurement process; in practice, however, the municipalities did not believe the PTA to be that interested in their involvement. The above quotation indicates that the PTA controlled the meeting by not taking account of the municipal requests and by discussing matters that concerned the regional cooperation body and not specifically the municipalities.

\subsubsection{Enrol the civil servants}

Another PTA strategy was to enrol municipal and regional cooperation body civil servants more directly. This meant that the PTA was mobilizing political resources via the civil servants, not directly from the politicians. For example, the PTA attempted to approach the civil servants by holding meetings with the "traffic technical group". This group consists of civil servants from each municipality, the county council, the regional cooperation body and the PTA [35]. ${ }^{3}$ In this group, the PTA informs the civil servants regarding current issues; some civil servants have a mandate to make decisions at the meeting, while others gather information and pass it on to their politicians before making any decisions [36].

Another way to shift the political resource mobilization from the politicians to the civil servant is found in the changing the role of the PTA's political board. The political board and the presidium can be seen as an organisational structure of control over the PTA since it possesses political power that the PTA need. Whether this strategy came from

\footnotetext{
${ }^{3}$ The civil servant from the county council is also invited to this group, but does not attend regularly.
}

the PTA or was an effect of positive synergy involving the PTA is hard to say from the empirical material. Today, the board consists of five members and the presidium (comprising the president, chair, and vice chair), compared with previously when each municipality and the county council had political representation on the PTA board. A politician in one municipality believed that this solution had shifted the power balance between the presidium and other politicians:

The new five-member board is more active, but it also feels as though the presidium (consisting of the president, chair, and vice chair) has acquired greater power, and I get the impression than many decisions have already been made by the presidium before they reach the board. [35]

The new organisational structure is seen as a problem from a local political perspective, since the transparency of decisions taken by the presidium is not as event compared to in the board where the decisions are finalized in for example protocols.

A conclusion that can be drawn is that the PTA, through the president and the civil servant, is the dominant coalition so far in the process. They can deploy their strategies within the rules of the game and, in this way, also regulate the process [19]. The strategy is to mobilize political resources by stressing the importance of dialogue with the principals. The attempt to enter into dialogue is initiated by personal meetings, letters, and board protocols. Clearly, the dialogue strategy was a way to enrol the principals and make them feel involved. In practice, the dialogue was not particularly communicative but instead informative. It has also been shown that the PTA mostly discussed the procurement with the civil servants in the municipalities and the regional cooperation body, for example, by holding meetings with the "traffic technical group", and was internally shifting the political focus from the PTA board to the PTA presidium.

\subsection{Political and financial resources create dependence between institutions}

This and the following section will focus on the "multiprincipal" function, i.e., the interaction between principals in relation to each other and the PTA. I will demonstrate that the principals take action based on resource interdependence. This interdependence is present on the institutional level (e.g., between the municipality and the county council), the actor-group level (e.g., between civil servants and politicians), and the individual level (e.g., between two civil servants). This section will provide an example of resource dependency between principals on the institutional level. 
One task in procurement planning is budgeting, i.e., how much are the principals willing to spend to achieve their goals? Budgeting is the exclusive responsibility of the municipalities and the county council, since their organizations exercise budgeting responsibility for all public transport in the county. When it comes to regional traffic, which this procurement process largely concerned, the county council pays for regional traffic, whereas the regional cooperation body has the planning responsibility for regional traffic. Representatives of the county council are invited to join different groups of deliberation (for example the traffic technical group described on page 11) but they often chose to not attend and don't use these type of power resources towards the PTA. It can therefore be said that the county council's actual involvement is mainly financial and they depend on the regional cooperation body's informational resources in the form of good decision-making support material. Local traffic is paid for by the municipalities; depending on the population, some municipalities pay more than others.

It seems, when analysing the interview material, that there is a tension between the municipalities and the county council concerning the budget. The county council and municipalities discussed the budgeting issue in different, and somewhat opposing, ways. The county council was very clear in its strategy towards the PTA and the municipalities: it first set a maximum budget and then asked the PTA what services it would get for that budget. Several municipalities seemed to take an opposite approach to the county council: they first specified their traffic service requirements, and only then - in some cases after the procurement was conducted - asked the PTA how much it would cost.

The municipalities are aware of this county council tactic of setting the budget first, and apparently in some cases regard it with envy [32]; as one civil servant stated, "perhaps we should also impose a budget restraint on the PTA?"

One municipal politician argued that it was important to know how much the required service would cost; however, she did not discuss the matter in terms of setting budget restraints. She said:

We actually talked about it with the one in charge of PTA issues, that it is important for us to know before [signing the procurement contracts] in what range the costs should be, so we don't get this shock afterwards ... [37]

I have the impression that it is sometimes difficult to discuss money in relation to traffic service demands. One civil servant explained that they specified their service demands in a meeting with the "traffic technical group". This municipality wished to include several safety demands, for example, new alcohol locks and three-point safety belts. Civil servants from other municipalities believed these demands would be too costly and raised the criticism at the meeting; however, they did not want their criticisms to be put on the protocol from the meeting. The civil servant who raised the issue explained it as follows:

... it was civil servants at the meetings who thought the demands were too expensive ... but then there was nobody who wanted it to be written in the protocol that would be too costly. [38]

One interpretation of the municipal behaviour is that it is somewhat "taboo" to put a price on human values, such as traffic safety. The municipality is the closest government level to the citizens, and it is often to it that citizens turn when they are disappointed at a public transport decision [39]. On the regional level, the county council has assigned the planning function to the regional cooperation body, so the organization setting the price is clearly distinguished from the organization specifying the service delivered for the price. This division of responsibility may appear less than transparent to citizens.

One civil servant also discussed the municipality's task, as it has a responsibility towards the PTA: "If the PTA doesn't manage to restrain its budget, then we as municipalities must be ready to go in and save the county council" [32].

The county council is clearly using its financial resources to influence both PTA behaviour ("We give you money - what will you give us back?") and municipal behaviour. Several times in the interviews, municipal politicians or civil servants stated that many municipalities have a strain economy. It is easy to get the impression that the municipalities felt that the county council was "cheap" in many ways, only talking about money and not the traffic requirements. It is also clear that the municipalities would rather discuss traffic than the budget. If the county council did not impose budget restraints, how expensive would public transport be? Or would the municipalities then assume the county role of setting a price for traffic? One possible conclusion is that the county council, by imposing budget restraints, allows the municipalities to focus on traffic demands within a set budget framework. The municipalities base their rhetoric on the fact that they are political organizations and are making decisions on behalf of the citizens. By letting the county council focus on the financial aspects, the municipalities can uphold their political agenda. In this sense, the principals (i.e., county councils and municipalities) are dependent on each other to keep their game strategy (i.e., the county council talks about finance and the municipalities make the political demands). 
It is also clear that the PTA has figured out that the county council "sets the price" while the municipalities focus on political demands for traffic services [31]. The current PTA president exploits this understanding in his dialogue with both the county council and the municipalities. It seems to be a successful strategy. A civil servant from one municipality described the former PTA president as not interested in dialogue with municipal actors. "The former president saw the municipalities as ATM machines"4 - the PTA simply stated how much money he needed without offering any details about how the money would be spent [32]. This was clearly a strategy that the current PTA president had not adopted; instead, he gave the impression of focusing on discussing, with municipal civil servants, the possibility of obtaining good transport service.

\subsection{Political resource mobilization by seeking cooperation} with others

It is also important to point out that some municipalities simply do not use their political resources to try to influence the service demands made in the procurement document. Some lower-population municipalities tend not to be active in the planning process. For example, one small municipality located next to a larger one lets the large municipality "drive" the issues. They are satisfied with this, and justify it by claiming that the strategy lets them spend their time on other matters [40].

The strategy of some smaller municipalities is to trade political influence. To put their own resources into something else, they must relinquish some of their political resources to a neighbouring municipality. By seeking cooperation with others, the municipality relinquishes some of its own political influence, while gaining resources (e.g., time) that can be used on other issues (similar behaviour is described by Pierre [22]).

\subsection{Resource dependency between politicians and civil servants}

As stated above, resource dependencies were also found between various actor groups. A common example of this is between politicians and civil servants working in the same organization. I will illustrate this type of resource dependency by citing examples from the municipalities.

In all municipalities, civil servants possess the most informational resources, and can use these resources to

\footnotetext{
${ }^{4}$ ATM stands for "automatic teller machine", in which you insert your banking card and from which you receive money. The quotation refers to the municipalities being treated as ATM machines, from which the PTA simply takes out money, without other communication.
}

"control" the information that reaches politicians. This is done formally in the form of written suggestions, and informally at meetings and in dialogue with politicians.

For example, the PTA put its thoughts on the procurement into a large pamphlet comprising three booklets. This pamphlet was sent to the municipalities, county council, and regional cooperation body for feedback [41]. There was a lot to read, and one civil servant said that he went through the pamphlet and highlighted what he believed the politicians needed to read, before passing it on to them [32].

I selected parts that concern our municipality. This was not easy because many parts were of concern. The book was not divided into chapters, each dealing with one municipality; instead, our issues were integrated into each chapter. [32]

In all municipalities, a civil servant then writes a proposal based on the opinions expressed in the pamphlet, which is then presented to the municipal board. The decision regarding this proposal is made by the municipal board and then sent to the PTA. In some municipalities, the politicians add some points to the proposal [32]; in other municipalities the proposal was not changed by the politicians.

Besides the fact that civil servants may "control" what information reaches politicians, this also confirms that resources are exchanged within municipalities. The civil servants use their informational resources to influence the outcome, but need the political resources to go through with the proposal. On the other hand, politicians possess the political resources but need informational resources to obtain their demands.

In the interviews, I asked the politicians how they obtained information about public transport issues, in view of the number of other questions that they as politicians must concern themselves with. How does a politician mobilize informational resources? Some cited experience, implying that politicians who have served on the municipal board a long time more easily understand public transport issues [35]. This means that more experienced politicians may gradually amass informational resources over time. Some politicians also attend seminars to which the PTA is invited to disseminate information and speak about public transport [35].

Some municipalities have also taken organizational measures to promote dialogue between the two actors groups. For example, the civil servants and politicians may have their offices near each other, sometimes in same corridor. In these cases, frequent informal dialogue is said to occur between politicians and civil servants, dialogue that helps the politicians obtain updated information on various transport issues [38]. 
A "younger" politician had a different view of resource mobilization [37]. She believed that dialogue with civil servants was crucial, and not only embraced the information but also asked the civil servants control questions. This also laid a responsibility on the politicians. She had noticed that few politicians ask civil servants questions (this point is in line with Hellström et al. [9]):

We are dependent on the civil servants ... because we do not have expertise in all areas. But what is important it is that ... politicians ask the civil servants so few control questions. ... I am surprised that there are so few questions. [37]

One way for politicians to mobilize informational resources is to ask questions - something that many may think should be an obvious approach, but one not used in all municipalities.

To conclude this section, it is important to stress resource dependency, i.e., both civil servants and politicians are dependent on each other, and the different actor groups have different strategies for mobilizing resources. There are formal procedures, such as attending meetings, but also more informal ones, such as meeting in the corridor. One may also conclude that different individuals make different efforts to use available resources, as the above quotation indicated.

4.5 Changing the rules of the game by mobilizing informational and political resources

This section deals with the regional organization, the regional cooperation body. The regional cooperation body has no budgetary influence over the PTA, so its financial resources are weak compared with those of the municipalities and the county council. Despite this, in the studied case, the regional cooperation body managed to mobilize other resources to influence the planning process. The main strategies the regional cooperation body used were the mobilization of informational resources and political mobilization by seeking cooperation with powerful individual actors. This section describes how resource exchange occurs horizontally, compared with the former case in which resource dependency occurred via hierarchal delegation chains.

Civil servants and politicians associated with the other principals (i.e., municipalities and the county council) describe the regional cooperation body in different ways. Some respondents state that the regional cooperation body has a history of being strongly influenced by its civil servants [42]. In the studied municipalities, the politicians felt that the regional cooperation body did not play a strong role in public transport issues; on the other hand, civil servants in at least some municipalities discussed public transport with the civil servants employed by the regional cooperation body. Some respondents stated that the regional cooperation body had not worked out perfectly; for example, one politician argued that the regional cooperation body's lack of budgetary influence was a problem if it was to decide on traffic issues:

The regional cooperation body doesn't have any budgetary influence over the PTA. I think it is important that the one that decides also pays. If you don't have the budgetary responsibility, then your suggestions can be far off the mark. [35]

However, several also stated that the division between the county council and the regional cooperation body had positive effects; for example, the regional cooperation body had raised certain issues, such as environmental ones. The county council must prioritize between health care and traffic, and traffic often comes in second place (see, e.g., [35]).

The relationship between the county council and the regional cooperation body seems to have changed due to the election in 2006. The PTA president stated that before the 2006 election, political dialogue between the PTA, regional cooperation body, and county council was very productive. Before 2006, the political orientation of the majority was the same in both the regional cooperation body and the county council; according to the PTA president, both the regional cooperation body and county council chairs were good friends. After the 2006 election, the political majorities of the different organizations changed, and now the county council was governed by a Conservative block, whereas the regional cooperation body had a Social Democratic chair. According to the PTA president, the dialogue between the county council and the regional cooperation body had become "frosty". Due to these frosty relations, the PTA president almost exclusively discussed policy issues with the county council as a single part [31]. In addition, civil servants working in the municipalities stated in interview that their main dialogue was with PTA directly, not via the regional cooperation body (see, e.g., [32]).

Despite the quite modest influence the regional cooperation body can exert on the municipalities, county council, and PTA, the regional cooperation body civil servant managed to become very involved in the procurement planning process. This prompted different reactions from the PTA and the municipalities. I will use this example to illustrate how informational resource mobilization in combination with political resource mobilization may be effectively used by an actor, in this case the regional cooperation body, that is subordinate to other principals. 
In late fall 2006, during the round of consultation; the regional cooperation body tried to became more active in the procurement process. It did this using various strategies to mobilize informational resources. One strategy was to involve an independent consulting firm. This firm was asked to produce recommendations regarding the future development of public transport system in the county, and to present its analyses and suggestions in a report. This report was then to be printed on behalf of the regional cooperation body and sent to all municipalities and the county council. The consulting firm made four alternative suggestions regarding the new traffic routing system, but was also required to analyse the alternative that the PTA had proposed in the procurement document (this was a fifth alternative [43]). Thus, the regional cooperation body had hired a consulting firm to evaluate the alternative that the PTA had designed.

The consultant's report can be seen as a regional cooperation body attempt to influence the outcome of the procurement document. Notably, the report preparation was not kept secret from the PTA and the municipalities. The consultant's report can also be seen as a tool for mobilizing political resources. To that end, a steering committee was connected to the report; it included two civil servants from the regional cooperation body, two civil servants from the PTA (the president and a civil servant, not the employee working on the procurement), two civil servants from two municipalities, and the head of the county council board (also a civil servant) [43]. So, besides mobilizing informational resources by hiring a consultant, the regional cooperation body invited strategically picked people to form a steering committee. The representatives were not geographically distributed over the county; for example, none of the municipalities in the south was represented on the steering committee, nor was the largest municipality represented (this municipality has the second-largest ownership share in the PTA after the county council). All the members of the steering committee were civil servants, and this group can be seen as exemplifying horizontal relationships among principals. When I asked the civil servants why they were elected to the steering committee, their answers differed. For example, the municipal representatives said that they were "forward thinking" and had regular contact with the regional cooperation body's civil servants [38]. The other participants believed that they had been selected for their titles or roles, to insure that the report was supported by all the organizations involved in the procurement. The county council representative stated that he did not play an active role, and was often connected to various groups, without any requirement to "do" something [44].

The consultant's report was published at the same time as the PTA conducted its round of consultations regarding the procurement content. The regional cooperation body sent the consultant's report to the PTA, municipalities, and county council.

What effect did the consultant's report have? Did the regional cooperation body manage to change the procurement content? One thing is for sure, the consultant's report created confusion among several actors in the municipalities and among the politicians on the PTA board [45]. For example, one municipality did not know how to value the consultant's report in relation to the opinions it was to give on the procurement documents [46]. A civil servant in one municipality stated that neither he nor "his" politicians had received any information about the consultant's report until it was already complete. He was very surprised to hear about the report, and confused as to why and by whom it was prepared. This civil servant decided to call his colleagues in two other municipalities to discuss the consultant's report. These three civil servants then turned to the PTA president and said that they needed more time to respond to the procurement document, if they were also to consider the conclusions of the consultant's report [32]. The regional cooperation body stated that it would await their response [45].

As a result, the PTA decided to extend the deadline of the round of consultations on the procurement document. The deadline was extended by 1 month, until 9 February 2007 [41]. The PTA also stated that "the consultant's report would be useful to read before giving any opinions on the procurement document" [46].

At this time, the PTA presidium set up a meeting with the regional cooperation body presidium. The aim of the meeting was to clarify the planned round of consultations and the procurement schedule, what role the consultant's report should play in relation to the procurement document, and the report's possible consequences [45]. The consultant's report had directly affected the procurement process, resulting in an extra meeting between the PTA and the regional cooperation body at which the regional cooperation body had a chance to discuss the on-going schedule of the procurement process.

What other effects did the consultant's report have? A civil servant at the regional cooperation body argued that the consultant's report was crucial to the outcome of the procurement document. He stated that "The PTA bought everything in the report" [47]. In addition, the PTA president thought the consultant's report was relevant, not in a way that changed the procurement document, but rather as it ensured that the process was on the right track. A local politician thought that the consultant's report was an addition to the procurement report. He believed that the consultant's report was more research based, which was also important to consider when conducting a procurement. Regarding the timing of the completion of the consultant's report, the informant believed it was right: "We had time to 
reflect on the report when it wasn't too old - we can't use old data in these kinds of processes" [42]. One consequence of the consultant's report, besides allowing the regional cooperation body to influence the procurement process, was that other actors (including the PTA) also used the report as a resource to gather political support for their decisions. Not only did the actor mobilizing power resources in the initial stage benefit from this resource mobilization, but other actors could also use the resources to their own benefit.

To others, however, the consultant's report meant little. Some civil servants did not recall the report at all [39], while others said that they knew about the report and had read it but felt it was not relevant to their municipality [32]. A few municipalities discussed the consultant's report, one way or another. Despite the extended time-frame, only five of twelve municipalities chose to cite the report in responding to the procurement document [48]. Notably, two of the municipalities that cited the consultant's report were represented on the steering committee for the consultant's report [49].

\section{Conclusions}

The "Scandinavian model" has gained popularity in Europe [1]. However, despite the increased popularity of the model, its procurement entity, often located in the public transport authority (PTA), has been criticized. For example in Sweden it is argued that the procurement entity has gained considerable autonomy within its political level, giving it a dominant position in planning the tender [7].

This article focuses on an unstressed part of the Scandinavian model: the interrelationship between the governmental actors involved in procuring public transport. Using Rhodes model of power dependency I have examined how this relationships are manifested. Rhodes' model portrays the actors as participants in a complex game in which they manoeuvre for advantages. In this context, each actor seeks to deploy its resources so as to maximize its influence while minimizing its dependence on the other players [20]. Rhodes [19] argue that, although certain dominant coalitions can condition the rules of the game, no single actor possesses all the constitutional, legal, organizational, financial, political, and informational resources it requires to achieve its goals.

I will start the concluding discussion with focusing on the resource dependency and discuss how various actors mobilize support using their own resources. Resource dependency is found on several levels throughout the planning process. It is present on the institutional level between principals, for example, between the county council and the regional cooperation body. On this level, we may conclude that there is interaction among principals; the multi-principal approach may be examined and further understood by addressing the institution-specific features of each principal (institutional relevance is also discussed by Hindmoor [50]). I also demonstrated that the principals, in interaction, may affect each other's roles in the process. For example, the county council and municipalities have two strategies regarding budgeting, i.e., the county council sets the price while the municipalities set the political demands; these strategies benefit each principal, creating dependency between them. Resource dependency is also found between actor groups, for example, between civil servants and politicians. This relationship can be seen as a classic principal-agent chain, and it is important to stress that hierarchical chains also exist in the planning process, but complemented by horizontal relationships. The example of the politician-civil servant relationship also addressed the fact that resource mobilization may be done formally or informally, for example, by attending meetings or just chatting in the corridor.

Rhodes' model also stresses that there is a dominant coalition that employs strategies within the rules of the game to regulate the exchange process. Regarding planning public transport procurement, the PTA is clearly the dominant organisation and the actors within the PTA form a dominant coalition. The PTA is not uncontrolled by its principals, but it sets the rules of the game, for example, by stating in letters what the principals are expected to do. As Rhodes argues, however, the PTA is dependent on political and financial resources from the principals to achieve its own agenda. The PTA amasses these resources mainly through dialogue with the principals. However, closer examination reveals that that these "dialogues" are more informational meetings than actual two-way dialogue. It is also clear that the PTA is mobilizing support for its proposals though the dialogue by playing the game differently depending on what the principal desires. For example, the PTA's approach to the municipalities is to discuss traffic service demands, while the PTA discusses financial matters with the county council, and joins a steering committee at the request of the regional cooperation body.

Another strategy of PTAs attempts to keep the power over the process regards the actions the PTA takes towards the regional cooperation body. There examples where the regional cooperation body are managing to mobilize political and informational resources that influence the game played by the PTA. Political resources were gathered on an individual, horizontal level by strategically selecting powerful people to form a steering committee. Informational resources were gathered by engaging the services of a consulting firm.

But the fact that the regional cooperation body does not possess monetary incitements (ownership) towards the PTA, is used by the PTA as an argument against involving 
the regional cooperation body in all matters. For example in situations in which the regional cooperation body agenda differs from that of the county council, the PTA excludes the regional cooperation body from involvement and, approaching the county council and certain municipalities.

It is thou important to point out that there is an exchange of resources between the regional cooperation body and the county council, in terms of planning and financial responsibility of the regional traffic questions. As presented in the material, the regional cooperation body and the county council had a good dialogue between each other during the time when the two organisations were governed by politicians with the same political colour (before the election in 2006). This may indicates two things. Firstly, in times when the regional cooperation body and the county council's political colour are the same, it is most likely that the resource exchange between the two organisations is larger, presumably the county council may also take in account power resources that the regional cooperation body uses (for example monitoring the PTA by direct participation in the technical traffic group) to control and influence the PTA. Further studies are thou needed before it is possible to determine if so the case is. Secondly, the change of political colour in one organisation at the county level may also change the strategy used by the PTA. As the material show, before the election in 2006 the regional cooperation body was to a greater extent included in dialogues that were taken place between the PTA and the county council.

This paper has provided an understanding of the interrelationships between the actors involved in planning public transport procurements, with a focus on the power relations between involved actors. It has been concluded that there is a dominant coalition within the PTA. This result is in compliance with findings regarding purchasing organisations in other policy areas (see e.g. [51]). However in order to validate the conclusions regarding the Swedish PTA as a general one for the Scandinavian model of public transport, it is recommend to conduct similar studies in Norway and Denmark.

Acknowledgements This study was financed by grants from VINNOVA, Sweden's innovation agency.

Open Access This article is distributed under the terms of the Creative Commons Attribution License which permits any use, distribution, and reproduction in any medium, provided the original author(s) and source are credited.

\section{References}

1. Longva F, Osland O (2010) Regulating the regulator: the impact of professional procuring bodies on local public transport policy and its effectiveness. Res Transp Econ 29:118-123
2. Bekken J-T, Longva F, Fearnley N, Osland O (2006) Norwegian experiences with tendered buss services. European Transport 33:29-40

3. van de Velde DM (2005) The Evolution of organizational forms in European public transport during the last 15 years. In: Hensher DA (ed) Competition and ownership in land passenger transport. Elsevier, Amsterdam

4. van De Velde DM (1999) Organisational forms and entrepreneurship in public transport: classifying organisational forms. Transport Pol 6:147-157

5. Enquist B (2003) Intressentdialoger inom kollektivtrafiken. En probleminventering och diskussion kring behovet av ett stödjande forsknings-och utvecklingsprogram för kollektivtrafikområdet. Karlstad University Studies 2003:4. Karlstads Universitet, Karlstad

6. Storbjörk S (2005) Kollektivtrafikpolitik, kunskapsutveckling och förnyelsearbete. Exemplet Östergötland. Innovativa kommuner 2005:1. Centrum för kommunstrategiska studier. Linköpings Universitet, Linköping

7. Christensson L (1997) Med ägarna vid ratten. Roller och ansvar i kollektivtrafiken. Landstingsförbundet och Svenska kommunförbundet. Kommentus Förlag, Stockholm

8. SOU 2009:39. En ny kollektivtrafiklag. Fritzes förlag: Stockholm

9. Hellström N, Meyer L, Sturesson J, KOMREV (2002) Aktiv ägarstyrning av kollektivtrafiken - Ett utvecklingsperspektiv. Underlagsrapport till Kollektivtrafikkommittén N 2001:05

10. Hansson, L. (2011/12, forthcoming) Public procurement in public transport: a research overview from a public-administrative perspective (prel. title). VTI-rapport. VTI: Linköping

11. Stanly J, Longva F (2010) Workshop report: a successful contractual setting. Res Transp Econ 29:80-88

12. Gwilliam K (2008) A review of issues in transit economics. Res Transp Econ 23:4-22

13. Thredbo (2010) Call for papers to the Thredbo 12 Conference. http://www.thredbo-conference-series.org. Accessed 2010-11-12

14. Hill M (2005) The public policy process, 4th edn. Pearson, Harlow

15. Dahl R (1957) The concept of power. Behav Sci 2:201-215

16. Widegren Ö (1989) Om latent och manifest makt. Statsvetenskaplig tidskrift 92:105-113

17. Rhodes RAW (1999) Control and power in central-local government relationships, 2nd edn. Ashgate, Aldershot

18. Panday PK (2006) Central-local relations, inter organizational coordination and policy implementation in urban Bangladesh. Asia Pac J Public Administration 28:41-58

19. Rhodes RAW (1992) Beyond Westminster and Whitehall: the subcentral governments of Britain, 2nd edn. Tyler \& Francis, London

20. Atkinson H, Wilks-Heeg S (2000) Local government from Thatcher to Blair: the politics of creative autonomy. Polity, Cambridge

21. Pierre J (ed) (2000) Debating governance. Authority, steering, and democracy. Oxford University Press, New York

22. Pierre J (1994) Den lokala staten: den kommunala självstyrelsens förutsättningar och restriktioner. Almqvist \& Wiksell, Stockholm

23. Bogason P (2000) Public policy and local governance. Institutions in postmodern society. Edward Elgar, Cheltenham

24. Thurén T (1997) Källkritik. Liber, Stockholm

25. George AL, Bennet A (2005) Case studies and theory development in the social sciences. MIT, Cambridge

26. Tansley O (2007) Process tracing and elite interviewing: a case for non-probability sampling. PS: Polit Sci Polit 40:765-772

27. Esaiasson P, Gilljam M, Oscarsson H, Wängnerud L (2004) Metodpraktikan. Konsten att studera samhälle, individ och marknad, 2nd edn. Nordstedts Juridik, Stockholm

28. March D, Smith M (2001) There is more than one way to do political science: on different ways to study policy networks issue. Polit Stud 49:528-541 
29. Kalmar länstrafik (2007) Trafikutredning/underlag för upphandling 2008

30. Kalmar länstrafik (2010) Årsredovisning 2009

31. Interview A. President, PTA, 2008-05-06

32. Interview B. Civil servant, Municipality, 2008-05-07

33. Kalmar länstrafik (2005) Brev från KLT till ägarna och regionförbundet "Trafikupphandling 2008" 2005-06-20

34. Kalmar länstrafik (2005) Brev från KLT till ägarna och regionförbundet. "Genomgång av KLT:s trafik inför trafikupphandlingen 2008" 2005-06-23

35. Interview D. Politician, Municipality, 2008-12-09

36. Interview C. Civil servant, Municipality, 2008-12-09

37. Interview E. Politician, Municipality 2007-05-28

38. Interview F. Civil servant, Municipality, 2008-04-28

39. Interview J. Politician, Municipality, 2007-05-28

40. Interview K. Politician, Municipality, 2008-12-05

41. Kalmar länstrafik (2007) Brev från KLT till ägarna och regionförbundet "Remiss Trafikutredning/underlag för upphandling". 2007-01-09
42. Interview G. Politician, Municipality, 2008-04-17

43. Regionförbundet (2006) Regionförstoring med kollektivtrafik Trivector, Regionförbundet 2006:91

44. Interview H. Chair, County council, 2008-11-26

45. Kalmar länstrafik (2006) KLT:s styrelseprotokoll daterat 2006-12-18

46. Emmaboda (2007) Emmaboda kommun styrelseprotokoll 200701-09

47. Interview I. Civil servant, Regional cooperation body, 2007-12-18

48. Kalmar länstrafik (2007) Brev från KLT till ägarna och regionförbundet Remissvar på KLTs trafikutredning/underlag för upphandling inför trafikåret 2008/09 och framåt. Brevet innehåller samtliga kommuners remissvar 2007-02-28

49. Hultsfreds kommun (2007)"Remissvar till KLT för trafikutredning/upphandling för trafik från 2008”. 2007-01-30

50. Hindmoor A (2006) Rational choice. Palgrave MacMilian, New York

51. Considine M (2001) Enterprising states. The public management of welfare-to-work. Cambridge University Press, Cambridge 